\title{
DIFFERENTIAL INEQUALITY CONDITIONS FOR DOMINANCE BETWEEN CONTINUOUS ARCHIMEDEAN T-NORMS
}

\author{
Susanne Saminger-Platz, Bernard De Baets and Hans De Meyer
}

Abstract. Dominance between triangular norms (t-norms) is a versatile relationship. For continuous Archimedean t-norms, dominance can be verified by checking one of many sufficient conditions derived from a generalization of the Mulholland inequality. These conditions pertain to various convexity properties of compositions of additive generators and their inverses. In this paper, assuming differentiability of these additive generators, we propose equivalent sufficient conditions that can be expressed as inequalities involving derivatives of the additive generators, avoiding the need of composing them. We demonstrate the powerfulness of the results by the straightforward rediscovery of dominance relationships in the Schweizer-Sklar t-norm family, as well as by unveiling some formerly unknown dominance relationships in the Sugeno-Weber t-norm family. Finally, we illustrate that the results can also be applied to members of different parametric families of t-norm.

Mathematics subject classification (2000): 39B62, 26D97, $26 \mathrm{~B} 35$.

Keywords and phrases: additive generator, convexity, dominance relation, geo-convexity, log-convexity, triangular norm (t-norm).

\section{REFERENCES}

[1] U. Bodenhofer, A Similarity-Based Generalization of Fuzzy Orderings, Schriftenreihe der Johannes-Kepler-Universität Linz, vol. C 26, Universitätsverlag Rudolf Trauner, 1999.

[2] B.De Baets and R. Mesiar, T-partitions, Fuzzy Sets and Systems, 97 (1998), 211-223.

[3] B. De Baets And R. Mesiar, Metrics and T-equalities, J. Math. Anal. Appl., 267 (2002), 331347.

[4] S. Díaz, S. Montes And B. De Baets, Transitivity bounds in additive fuzzy preference structures, IEEE Trans. Fuzzy Systems, 15 (2007), 275-286.

[5] B. Lafuerza Guillén, Finite products of probabilistic normed spaces, Rad. Mat., 13, 1 (2004), 111-117.

[6] W. Jarczyk and J. Matkowski, On Mulholland's inequality, Proc. Amer. Math. Soc., 130, 11 (2002), 3243-3247.

[7] Logical, Algebraic, Analytic, and Probabilistic Aspects of Triangular Norms, edited by E. P. Klement and R. Mesiar, Elsevier, Amsterdam, 2005.

[8] E. P. Klement, R. Mesiar And E. PAP, Triangular Norms, Trends in Logic. Studia Logica Library, vol. 8, Kluwer Academic Publishers, Dordrecht, 2000.

[9] E. P. Klement, R. Mesiar And E. Pap, Triangular norms. Position paper I: Basic analytical and algebraic properties, Fuzzy Sets and Systems, 143 (2004), 5-26.

[10] E. P. Klement, R. Mesiar And E. PAP, Triangular norms. Position paper II: General constructions and parameterized families, Fuzzy Sets and Systems, 145 (2004), 411-438.

[11] E. P. Klement, R. Mesiar And E. PaP, Triangular norms. Position paper III: Continuous t-norms, Fuzzy Sets and Systems, 145 (2004), 439-454.

[12] R. MEsiar AND S. SAminger, Domination of ordered weighted averaging operators over t-norms, Soft Computing, 8 (2004), 562-570.

[13] H. P. Mulholland, On generalizations of Minkowski's inequality in the form of a triangle inequality, Proc. London Math. Soc., 51, 2 (1950), 294-307.

[14] S. SAminger, Aggregation in Evaluation of Computer-Assisted Assessment, Schriftenreihe der Johannes-Kepler-Universität Linz, vol. C 44, Universitätsverlag Rudolf Trauner, 2005. 
[15] S. Saminger, B. De Baets And H. De Meyer, On the dominance relation between ordinal sums of conjunctors, Kybernetika, 42, 3 (2006), 337-350.

[16] S. Saminger, B. De Baets And H. De Meyer, A generalization of the Mulholland inequality for continuous Archimedean t-norms, J. Math. Anal. Appl., 345, 2 (2008), 607-614.

[17] S. Saminger, R. Mesiar AND U. Bodenhofer, Domination of aggregation operators and preservation of transitivity, Internat. J. Uncertain. Fuzziness Knowledge-Based Systems, 10 (2002), 11-35.

[18] S. SAminger, P. SARKoci AND B. De BAeTs, The dominance relation on the class of continuous t-norms from an ordinal sum point of view, Lecture Notes in Artificial Intelligence, 4342 (2006), 334354.

[19] P. SARKOCI, Domination in the families of Frank and Hamacher t-norms, Kybernetika, 41 (2005), 345-356.

[20] P. SARKOCI, Dominance is not transitive on continuous triangular norms, Aequationes Math., 75 (2008), 201-207.

[21] B. Schweizer And A. Sklar, Probabilistic Metric Spaces, North-Holland, New York, 1983.

[22] H. SHERwood, Characterizing dominates on a family of triangular norms, Aequationes Math., 27 (1984), 255-273.

[23] R. M. TARDIFF, Topologies for probabilistic metric spaces, Pacific J. Math., 65 (1976), 233-251.

[24] R. M. TARDIFF, On a functional inequality arising in the construction of the product of several metric spaces, Aequationes Math., 20 (1980), 51-58.

[25] R. M. TARDIFF, On a generalized Minkowski inequality and its relation to dominates for t-norms, Aequationes Math., 27 (1984), 308-316.

[26] L. VAlverde, On the structure of F-indistinguishability operators, Fuzzy Sets and Systems, 17 (1985), 313-328. 